\title{
Radiographic assessment of the cup orientation after total hip arthroplasty: a literature review
}

\author{
Jing-Xin Zhao ${ }^{1,2 \#}$, Xiu-Yun Su ${ }^{1,3 \#}$, Zhe Zhao $^{4}$, Ruo-Xiu Xiao ${ }^{5}$, Li-Cheng Zhang ${ }^{1,2}$, Pei-Fu Tang ${ }^{1,2}$ \\ ${ }^{1}$ Department of Orthopaedics, the First Medical Centre, Chinese PLA General Hospital, Beijing 100853, China; ${ }^{2}$ National Clinical Research Center \\ for Orthopedics, Sports Medicine \& Rehabilitation, Beijing 100853, China; ${ }^{3}$ Intelligent and Digital Surgery Innovation Center, Southern University \\ of Science and Technology Hospital, Shenzhen, Guangdong 518055, China; ${ }^{4}$ Department of Orthopaedics, Beijing Tsinghua Changgung Hospital, \\ School of Clinical Medicine, Tsinghua University, Beijing 102218, China; ${ }^{5}$ School of Computer and Communication Engineering, University of \\ Science and Technology Beijing, Beijing 100083, China \\ Contributions: (I) Conception and design: LC Zhang, PF Tang; (II) Administrative support: None; (III) Provision of study materials or patients: None; \\ (IV) Collection and assembly of data: JX Zhao, RX Xiao; (V) Data analysis and interpretation: XY Su, Z Zhao; (VI) Manuscript writing: All authors; \\ (VII) Final approval of manuscript: All authors. \\ \#These authors contributed equally to this work. \\ Correspondence to: Pei-Fu Tang, PhD, MD; Li-Cheng Zhang, PhD, MD. Department of Orthopaedics, The First Medical Centre, Chinese PLA \\ General Hospital, Beijing 100853, China. Email: pftang301@163.com; zhanglcheng218@126.com.
}

\begin{abstract}
Optimal acetabular cup orientation is of substantial importance to good long-term function and low complication rates after total hip arthroplasty (THA). The radiographic anteversion (RA) and inclination (RI) angles of the cup are typically studied due to the practicability, simplicity, and ease of interpretation of their measurements. A great number of methods have been developed to date, most of which have been performed on pelvic or hip anteroposterior radiographs. However, there are primarily two influencing factors for these methods: X-ray offset and pelvic rotation. In addition, there are three types of pelvic rotations about the transverse, longitudinal, and anteroposterior axes of the body. Their effects on the RA and RI angles of the cup are interactively correlated with the position and true orientation of the cup. To date, various fitted or analytical models have been established to disclose the correlations between the X-ray offset and pelvic rotation and the RA and RI angles of the cup. Most of these models do not incorporate all the potential influencing parameters. Advanced methods for performing X-ray offset and pelvic rotation corrections are mainly performed on a single pelvic AP radiograph, two synchronized radiographs, or a two-dimensional/three-dimensional (2D-3D) registration system. Some measurement systems, originally developed for evaluating implant migration or wear, could also be used for correcting the X-ray offset and pelvic rotation simultaneously, but some drawbacks still exist with these systems. Above all, the 2D-3D registration technique might be an alternative and powerful tool for accurately measuring cup orientation. In addition to the current methods used for postoperative assessment, navigation systems and augmented reality are also used for the preoperative planning and intraoperative guidance of cup placement. With the continuing development of artificial intelligence and machine learning, these techniques could be incorporated into robot-assisted orthopaedic surgery in the future.
\end{abstract}

Keywords: Acetabular cup; radiographic angle; pelvic rotation; X-ray offset

Submitted Sep 19, 2019. Accepted for publication Dec 17, 2019.

doi: 10.21037/atm.2019.12.150

View this article at: http://dx.doi.org/10.21037/atm.2019.12.150 


\section{Introduction}

Optimal acetabular cup orientation is of substantial importance to good long-term function and low complication rates after total hip arthroplasty (THA). Improper cup positioning always leads to limited rangeof-motion, accelerated wear, and early dislocation postoperatively. Anteversion and inclination are two primary indicators of the cup orientation in THA (1), which can be measured on a plain radiograph $(2,3)$ and were named the radiographic anteversion (RA) and inclination (RI) angles, respectively, by Murray (4) (Figure 1). In addition, the other two pairs of Murray angles, the anatomical anteversion (AA) and inclination (AI) angles and the operative anteversion $(\mathrm{OA})$ and inclination angles, could be transformed into each other using trigonometric functions but were wrongly used in the literature.

Some specific ranges for the RA/RI angle recommended by Lewinnek et al. (3) and others $(5,6)$ have also been widely accepted as the "safe zone" for cup placement in THA. However, to date, a plethora of different methods for measuring the cup orientation have been proposed and are inconsistent among each other. As a simple, cheap, and easily available imaging modality, the plain radiograph is still the mainstream tool for the postoperative assessment of cup orientation. Multiple radiographic measurement methods have been proposed since the 1970s.

However, there is a discussion to be had about the reliability and validity of these radiographic methods. Indeed, cup angle interpretation is multifactorial and dependent on both extrinsic and intrinsic factors (7). The cup orientation can only be correctly interpreted with reliable results after incorporating all the influencing factors into the calculation process. As the two most important extrinsic determinants of cup orientation, the $\mathrm{X}$-ray offset and pelvis orientation have been analysed with different observational results in numerous previous studies. To minimize the effects of the X-ray offset and pelvic rotation on the radiographic evaluation of the cup orientation, other measurement methods involving complicated algorithms and advanced equipment and technology have also been developed for precisely assessing the cup orientation intra- or postoperatively. Different methods have their own pros and cons according to their applications and availability.

Although some studies have disclosed significant variation in the current assessment methods of cup orientation (8) and analysed the pitfalls of these methods on how to correctly determine the cup orientation in
THA regarding pelvic rotation (9), a critical analysis of the reasons for this inconsistency, the effects of the X-ray offset and pelvic rotation, and the previously established correction methods is still lacking. The rest of this review is organized as follows. The section titled "Radiographic measurement methods of cup angles" presents the conventional measurement methods of the radiographic angles of the cup, including an overview of radiographic measurement methods based on the hip or pelvic anteroposterior (AP) and lateral radiographs and reliability and validity studies of the conventional measurement methods. In the section titled "Influencing factors of the radiographic angles of the cup", the influencing factors of the radiographic angles of the cup are introduced, the $\mathrm{X}$-ray offset and the pelvic rotation. In the section titled "Advanced methods for evaluating the X-ray offset and pelvic rotation", we present some advanced methods for correcting the X-ray offset and pelvic rotation. Finally, in the "Discussion" section, we discuss the advantages and disadvantages of the various types of measurement methods used today and then summarize the challenges and future prospects in the radiographic assessment of cup orientation.

\section{The radiographic measurement methods of the cup angles}

\section{Overview of the radiographic measurement methods}

Most radiographic measurement methods of cup angles are performed on AP X-ray films, including hip and pelvic radiographs. Others use a lateral radiograph of the hip as the measurement tool.

\section{Hip AP X-ray}

Since McLaren proposed the earliest radiographic measurement method in 1973 (2), many researchers have developed different variants and measurement tools based on the original algorithm. All of these methods are based on a basic projection phenomenon in which the cup opening can be projected by a parallel beam from a circle to an ellipse on the $\mathrm{X}$-ray film. The correspondence between the spatial circle and the planar ellipse can be interpreted with the cup anteversion, of which the arcsine value can be calculated with the shorter to longer axis of the ellipse projected onto AP X-ray film. Although the X-ray has no parallel beam in the real world, this relationship between the circle and ellipse persists on hip-centred AP radiographs, which was verified in an analytical study (10). 


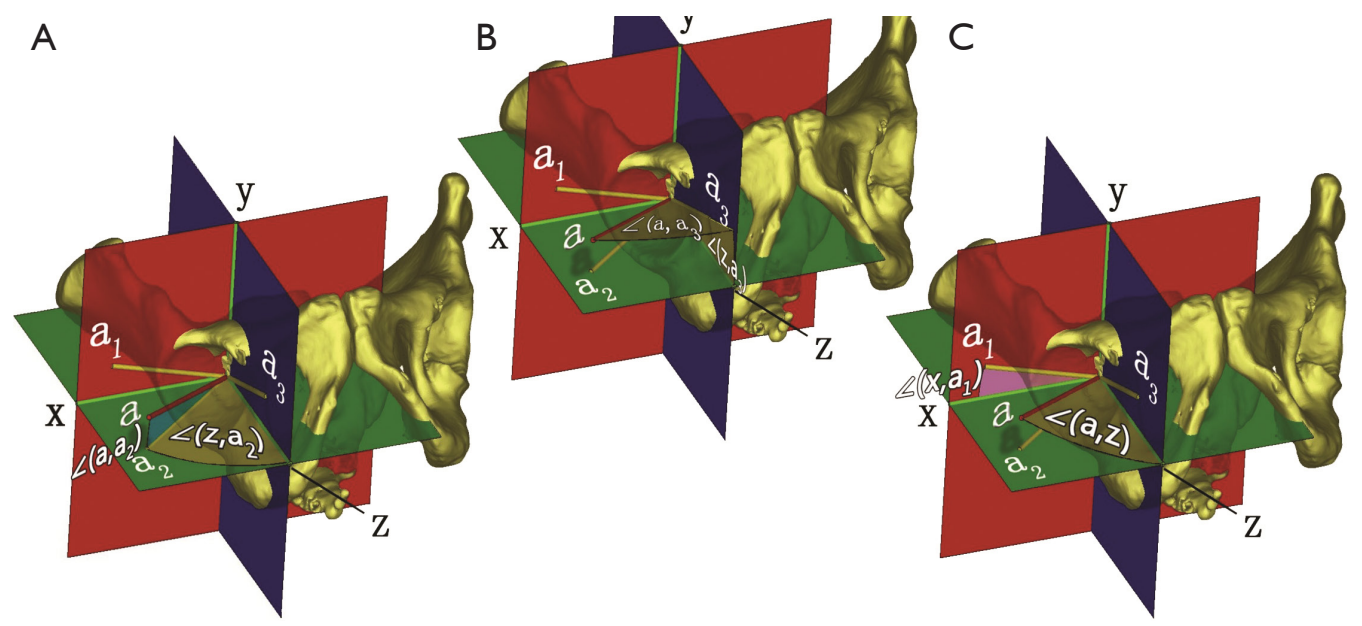

Figure 1 Three pairs of the acetabular/cup angles defined by Murray. x, y, and $z$ are the transverse, anteroposterior, and longitudinal axis of the body. xz, xy, and yz constitute the axial, coronal, and sagittal plane, respectively. a represents the axis of the acetabular or cup, of which its projection in the axial, coronal, and sagittal plane are a1, a2, and a3, respectively. (A) The RA and inclination angles are indicated by $\angle$ (a, a2) and $\angle(\mathrm{z}, \mathrm{a} 2)$; (B) the OA and inclination angles are indicated by $\angle(\mathrm{a}, \mathrm{a} 3)$ and $\angle(\mathrm{z}, \mathrm{a} 3)$; (C) the AA and inclination angles are indicated by $\angle(\mathrm{x}$, a1) and $\angle(a, z)$.

To calculate the cup anteversion, Ackland et al. used the general formula of the ellipse to calculate its shorter axis (11), while others developed similar methods (12-17). Visser et al. established a mathematical method combining the general formula of the ellipse and the trigonometric functions for the measurements (18). Additionally, other modified methods have been proposed according to basic geometrical relationships (19-22). Based on these algorithms, different measurement tools (23) and software $(24,25)$ were established. Using McLaren's method, the RadLink software was developed to intraoperatively help place the cup within the target range (24). Zingg et al. incorporated the rotation matrix algorithm to evaluate the cup orientation with a C-arm intraoperatively (26).

Although these methods were used in hip AP radiographs (Figure 2), they were also performed on pelvic $\mathrm{AP}$ radiographs in other studies.

\section{Pelvic AP X-ray}

Similar to McLaren's study, Lewinnek also proposed a similar measurement method based on the same trigonometric relationship between the longer and shorter axis of the ellipse (3). Thereafter, others also used similar methods to measure the cup orientation intra- (5) or postoperatively $(27,28)$; meanwhile, the TraumaCad software used by Schwarzkopf et al. (29) was developed based on these methods. However, all these studies performed measurements on the pelvic AP radiograph without considering $\mathrm{X}$-ray divergence and the distorted silhouette of the cup opening.

Martell et al. developed a semi-automated computerassisted technique, named the Hip Analysis Suite (HAS), for detecting polyethylene wear in THA based on edge detection (30). During measurement of the cup orientation, edge detection was used to help determine the edge of the ellipse projection of the cup opening. Barrack et al. also used the HAS to calculate the cup angles on pelvic AP radiographs (31). Penenberg et al. used Radlink to measure the intraoperative RA angle and compared it with the postoperative measurements obtained using Martell software (5). In another study, Callanan et al. (32) added an additional lateral radiograph to distinguish anteverted from retroverted cups. Importantly, the $\mathrm{X}$-ray offset was not considered in many of these studies $(5,30-32)$.

\section{Lateral radiographs}

In addition to the above-mentioned measurement methods involving AP radiographs, other methods have been performed on hip lateral radiographs, such as the crosstable lateral radiograph $(13,14,33-39)$. 
A

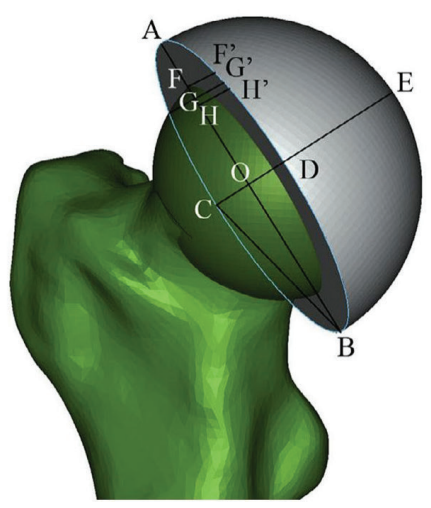

B

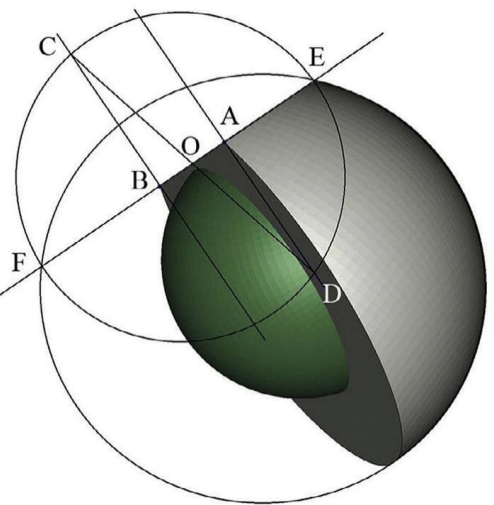

C

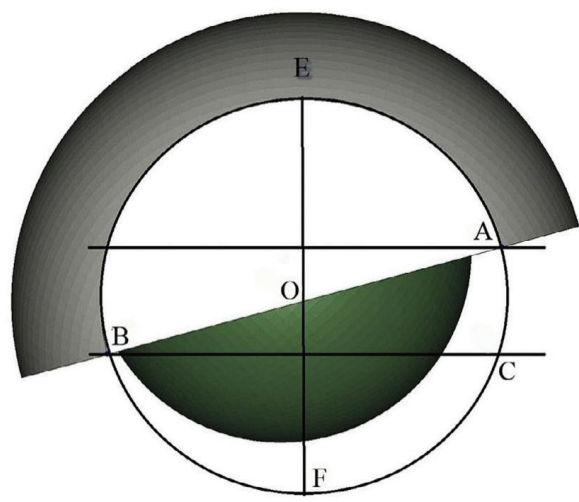

Figure 2 Some of previous radiographic measurement methods on the pelvic or hip AP radiograph (10). (A) The methods of Ackland (11), Hassan (15), and Pradhan (16) rely on different points acquired on the longer axis of the ellipse projection, which can be used to determine the shorter axis according to the general equation of ellipse. With Liaw's method (20), the RA angle is arcsine of the shorter to longer axis; (B,C) the methods of Kosiyatrakul et al., Bachhal et al. and Fabeck et al. can be shown with another circle and a change of view. Details of the explanation can be found in Figure 3 in (10).

However, the patient position is poorly standardized and the $\mathrm{X}$-ray beam angle used varies across studies that analysed cross-table lateral radiographs. The degree of contralateral hip flexion is inconsistent, with $45^{\circ}(40,41)$, $90^{\circ}(41,42)$, or some arbitrary degree (13) reported across studies. Furthermore, the beam direction used also varies, with $30^{\circ}(13)$ or $45^{\circ}$ reported $(38,39)$. Herrlin et al. (13) and Ghelman et al. (43) determined that the inclination of the cup opening relative to the X-ray table could not represent the RA angle of the cup unless the cup opening was projected as a line onto the cross-table lateral radiograph, which was dependent on the RI angle of the cup and was difficult to achieve in clinical activities.

Another concern inherent to the cross-table radiograph was that flexion of the contralateral hip might cause pelvic extension or posterior tilt, which would result in increased acetabular anteversion to an unknown degree (35).

\section{Reliability and validity assessment of the radiographic measurement methods}

A variety of studies have been performed to test the reliability and validity of the various measurement methods using either the hip or pelvic AP or cross-table lateral radiograph to date. Some of them used phantom models to compare different measurement methods, while others compared the measurement results between radiographic and CT-based methods.

The inter- and intra-observer reliability of the Hassan method and the cross-table measurement method were verified in two studies without referencing other methods $(44,45)$. In addition, most of the radiographic measurement methods established previously were compared with reference values either in a model test or from clinical studies. As shown in the summary in Table 1, most of the comparative or reliability studies reported previously did not use uniform study designs and outcomes in terms of the hip or pelvic radiographs, intra- or postoperative fluoroscopy, the standing or supine position, the reference plane (e.g., $\mathrm{AP}$, axial or sagittal CT image, or the coronal plane of the body), the targeted angles of the cup (e.g., the RA, OA or AA angle), and the measurement technique used as the control reference. Most importantly, the X-ray offset was not incorporated into the calculation procedure when these methods were performed on the pelvic AP radiographs.

\section{Influencing factors of the radiographic angles of the cup}

The X-ray offset and pelvis orientation have been considered to be the two most important extrinsic influencing factors in the radiographic measurement of the cup orientation.

\section{$X$-ray offset}

The phenomena of the variable silhouette of the cup opening caused by variability in the relative position 


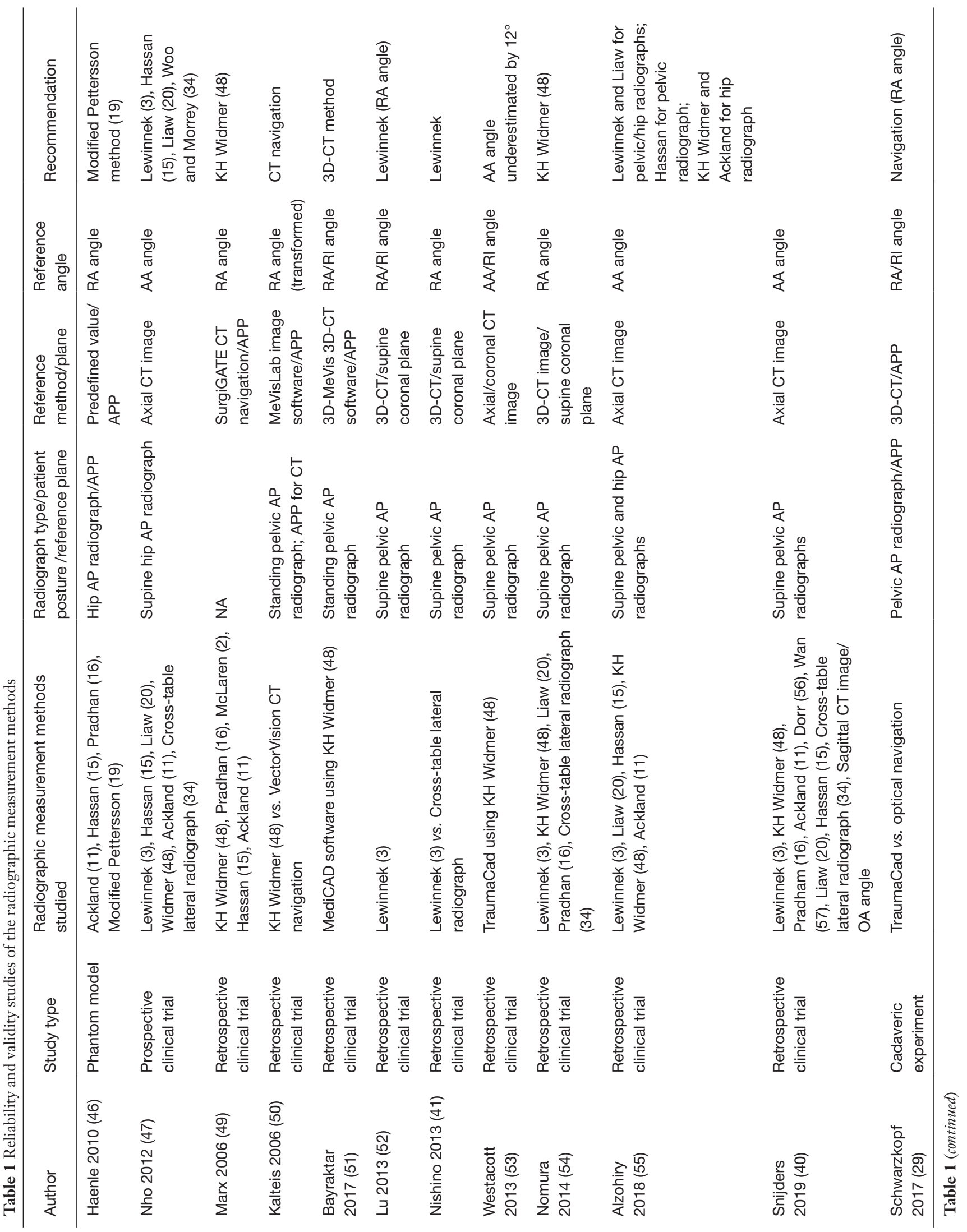




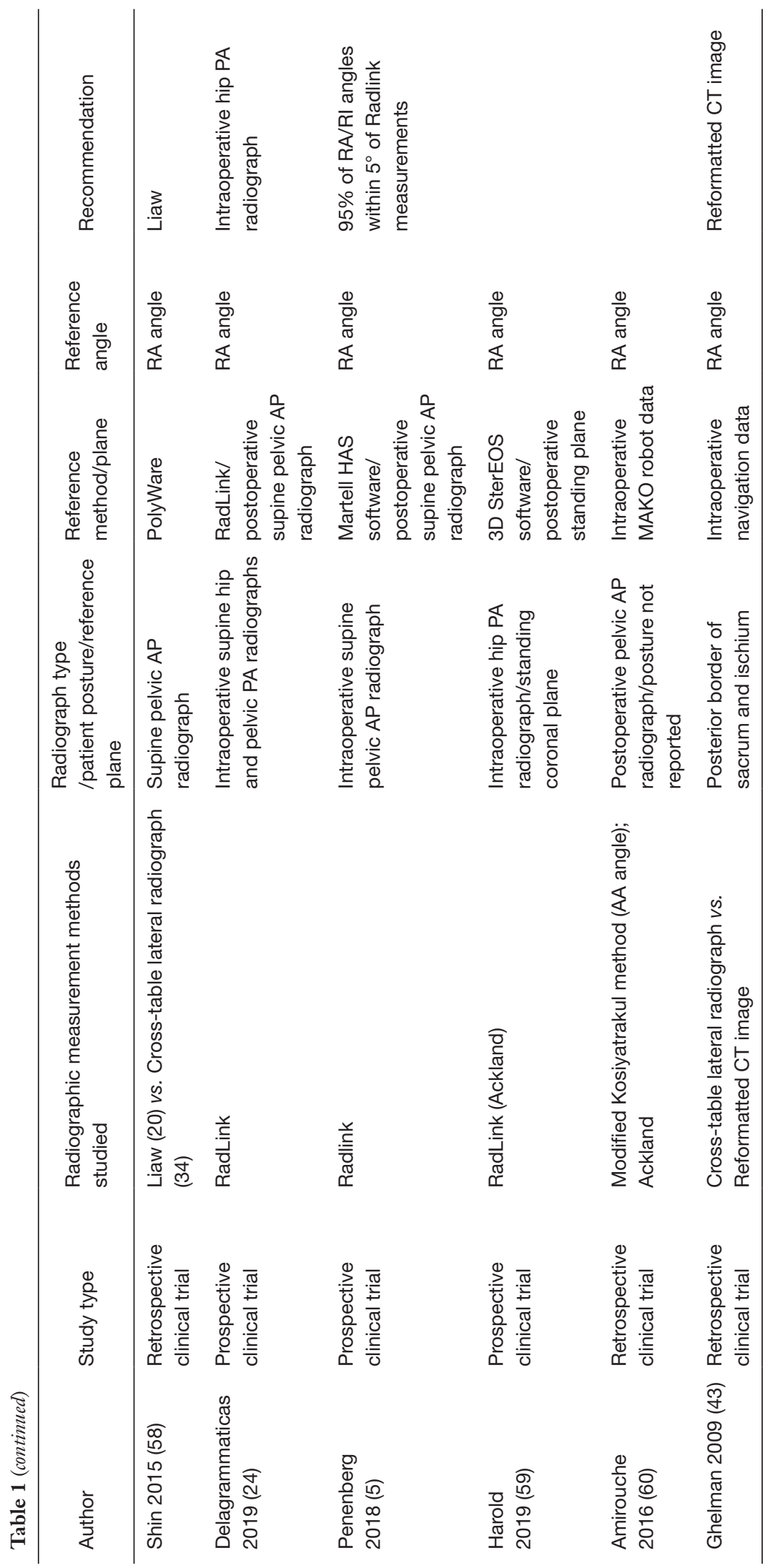




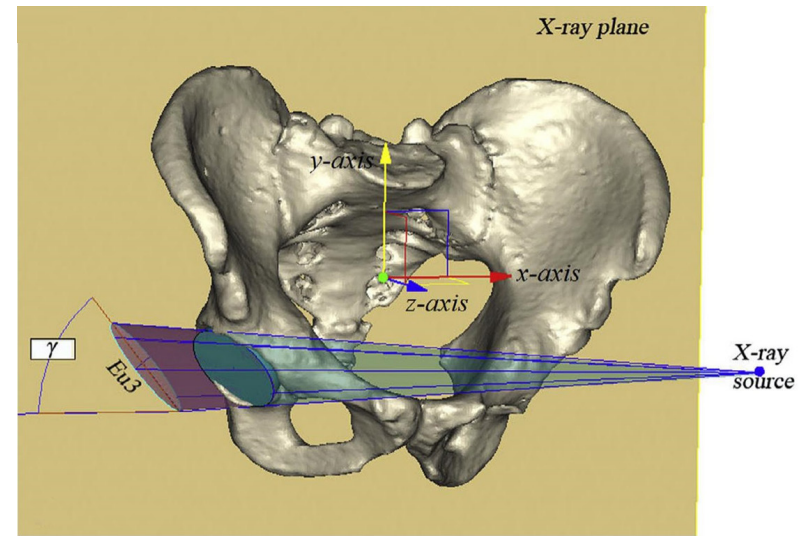

Figure 3 A cone model for correcting the X-ray offset and measuring the radiographic angles of the cup (10). Eu3 represents the ellipse projection of the cup opening.

between the cup and the X-ray beam source was disclosed in 1975, which was attributed to divergent rays or the X-ray offset in the pelvic AP radiograph $(15,61)$. Pettersson et al. used the transverse translation of the $\mathrm{X}$-ray source from the pelvic $\mathrm{AP}$ view to the hip $\mathrm{AP}$ view to judge the anteversion and retroversion of the cup (12), which was also used in later studies $(16,62,63)$.

Goergen and Resnick proposed a correction factor of an additional $5^{\circ}$ for the RA angle for the symphysiscentred pelvic AP radiograph relative to that of the hip AP radiograph, while the correction factor was variable with the varying relative position of the cup and $\mathrm{X}$-ray offset (61). Other researchers had similar findings $(11,16,48,62,63)$. Regardless of the incorrect interpretation of the Lewinnek method, Dorr et al.'s study only presented a predefined setting for the cup position and pelvic rotation (62).

In addition to the $\mathrm{X}$-ray offset, after measuring radiographs of 152 THA procedures, Karl-Heinz Widmer found that the RA angle was also slightly dependent on the true cup inclination (48). Rueckl et al. aligned the intra- and preoperative pelvic postures on the radiographs and found that an additional $5^{\circ}$ correction factor was needed to correct the intraoperative RI angle for the $\mathrm{X}$-ray offset (64).

For the above-described studies, no theoretical evidence was presented to support these proposals. With CT-based measurements as the reference, Westacott $e t$ al. discovered a correlation between the RA/RI angles and their CTderived counterparts (53). Widmer et al. (65) also stressed that the RA angle measured on the pelvic AP radiograph was nothing but a first approximation that needed to be corrected unless measured on the hip-centred AP radiograph.

Liaw et al. established a correction method for the $\mathrm{X}$-ray offset in the pelvic AP radiograph by modifying Karl-Heinz Widmer's method (66). Furthermore, the relationship between the true RA angle and its estimated error on the pelvic AP radiograph was expressed as a curve dependent on the true RI angle. More specifically, Schwarz et al. performed a phantom model study to quantitatively investigate the influence of the X-ray offset on the cup angles (67). Based on the observation that translating the $\mathrm{X}$-ray beam medially and cranially from the centre of the hip could decrease the RA angle of the cup, they established a modified method of differentiating between anteversion and retroversion of the cup by means of a second X-ray and correcting the RA angle by adding horizontal and vertical correction factors, which could be calculated in line with Liaw's correction method for the transverse X-ray offset and Tannast and Wan's method for pelvic tilt correction.

In contrast to the linear model of Schwarz et al., Zhao et al. incorporated the influencing factors of $\mathrm{X}$-ray offset into a mathematical model that involved the rotation matrix of the projection transformation between the spatial circle and its ellipse projection in the X-ray plane (68) (Figure 3). The varying rules between the $\mathrm{X}$-ray position and the cup orientation in $3 \mathrm{D}$ space could be depicted as different types of surfaces or curves dependent on different groups of unknown variables in the formulae. Given the theoretical nature of Zhao et al.'s study, further in vitro experiments should be performed to verify their conclusions.

\section{Pelvic rotation}

Pelvic rotations involve the transverse, longitudinal, and anteroposterior axis of the body, which are referred to as tilt, axial rotation, and obliqueness, respectively, in this study for clarification. The intersubject variation of pelvic tilt was studied mostly with inconsistent results and influenced the cup orientation significantly, especially for pelvic AP radiographs, which cannot indicate the degree of individual pelvic tilt directly.

The lateral radiograph was the most convenient tool for measuring the pelvic tilt. Shon et al. measured the pelvic tilt among four postures using the lateral radiographs of 40 patients and found that the pelvis tilted posteriorly $26.5^{\circ}$, $8.4^{\circ}$, and $13.4^{\circ}$ from the supine position to the sitting, standing, and lateral decubitus positions, respectively (69). Heckmann et al. incorporated the sacral slope into the 
evaluation of the relationship between the cup's AA angle and late dislocation after THA (70). After adjusting the gantry angle of the CT scan, Anda et al.'s cadaveric study presented a ratio of $0.5^{\circ}$ variation in the acetabular AA angle to $1^{\circ}$ of pelvic tilt (71). Lazennec et al. established a similar reformatted CT-based method to measure the AA angle after incorporating the pelvic tilt measured on the lateral radiographs of different postures (72).

In addition to lateral radiographs and CT scans, some anatomical studies have observed that the pelvic tilt could cause a change in the acetabular crossover on pelvic AP radiograph (71,73-75). Tannast et al. analysed six pelvic anatomical parameters from the pelvic AP radiographs of 104 patients, one of which showed the strongest correlation with the pelvic tilt measured on the lateral radiograph (76). By doing so, they established a mathematical correction model for estimating the pelvic tilt based on the postoperative pelvic AP radiograph.

Similar to the offset effect caused by X-ray translation, modifying the angle of the $\mathrm{X}$-ray beam (11), such as the pelvic inlet view $(5,15)$, can help with evaluating the difference between the anteversion and retroversion of the cup. When viewing towards the pelvic inlet, the abduction and anteversion angles were reduced for an anteverted cup but increased for a retroverted cup (12,77).

Table 2 summarizes the studies performed on the relationship between the pelvic rotations and the RA and RI angles of the cup using the above-mentioned radiographic measurement methods. Most of these studies were observational studies. Grammatopoulos et al. (81) used the EBRA software to evaluate the impact of the orientation of the pelvis between lateral decubitus and supine positions during the operation. Wolf et al. $(87,88)$ performed a model test to establish a relationship between the pelvic rotation and the measurements of different angles of the cup. Derbyshire (89) developed a series of mathematical equations to evaluate the effects of different types of pelvic rotations on cup wear. Except for these three studies, researchers have only analysed one or two influencing factors, such as pelvic tilt and axial rotation. Similar to the effect of the X-ray offset, the interactive effect of the true RI angle of the cup and the pelvic rotation on the RA angle of the cup has also been observed in some studies $(12,85)$. The $\mathrm{X}$-ray offset was also incorporated into the effect of pelvic rotation on the measurement of the cup angles in some observational, in vitro phantom studies $(57,83,84)$. However, these established methods or models did not analyse the synergetic effect of the pelvic rotation and X-ray offset in an accurate manner, which was merely approximated in some simulated or fitted models, regardless of other parameters influencing the calculation. Based on a previously established cone model, Zhao et al. established an equation for a cone and accurately analysed the effects of the pelvic rotations about each axis on the RA/RI angles after incorporating the $\mathrm{X}$-ray offset and the position and orientation of the cup (90).

\section{Advanced methods for evaluating the X-ray offset and pelvic rotation}

Different from the traditional measurement methods, which were mainly performed on a single radiograph, some advanced methods incorporated more complicated equipment, algorithms and methods.

\section{Single pelvic AP radiograph}

Due to the inherent deficiency of X-ray film, it is difficult to accurately evaluate the pelvic tilt using a single pelvic AP radiograph; however, the X-ray offset can be corrected as much as possible with some complicated algorithms with or without edge detection.

\section{Mathematical method}

The earliest method involving a mathematical algorithm was proposed by Seradge in 1982 (91). His method was based on a series of geometric transformations with a specified parameter range in the model, which limited its application.

To reveal the effect of pelvic rotation on the cup angles, Jaramaz et al. (92) developed a new method of geometric reconstruction and measured the cup orientation using this new method and Seradge's method. When compared with the intraoperative navigation measurements, the results displayed a significant effect of pelvic rotation on the RA angle. No details of their method were disclosed.

Derbyshire also developed an advanced algorithm similar to Seradge's method (93). However, in this method, the RI angle needed to be corrected before the RA angle; furthermore, his derivation process was difficult to follow and conveniently interpret by the reader.

In Amiri et al.'s study, a multiplanar radiographic method was used to compensate for the X-ray offset (94). Using this method, the relationship between the measurement errors caused by the X-ray offset and the true cup orientation was established and simulated. In a study of the radiographic assessment of cup wear, Stuart 


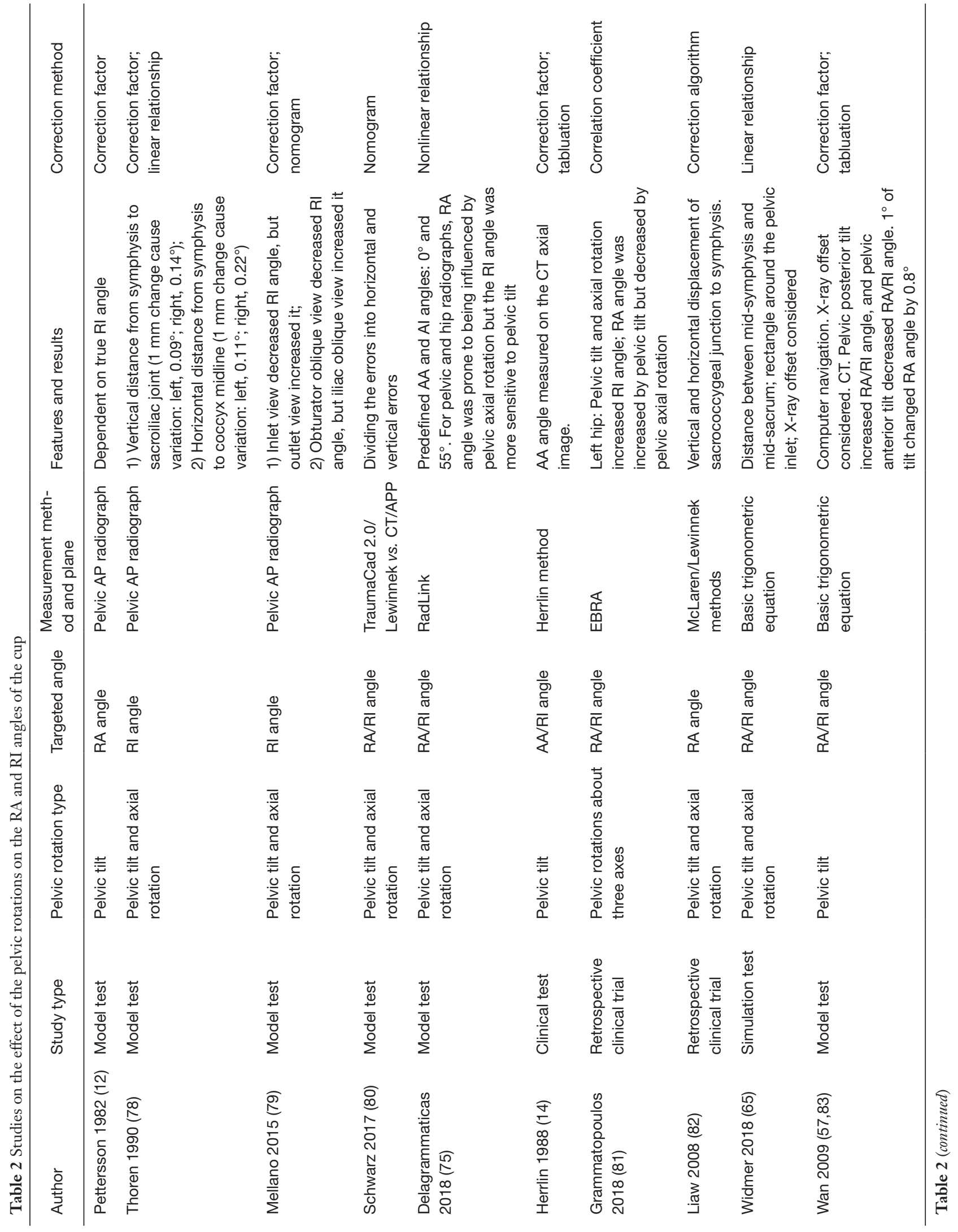




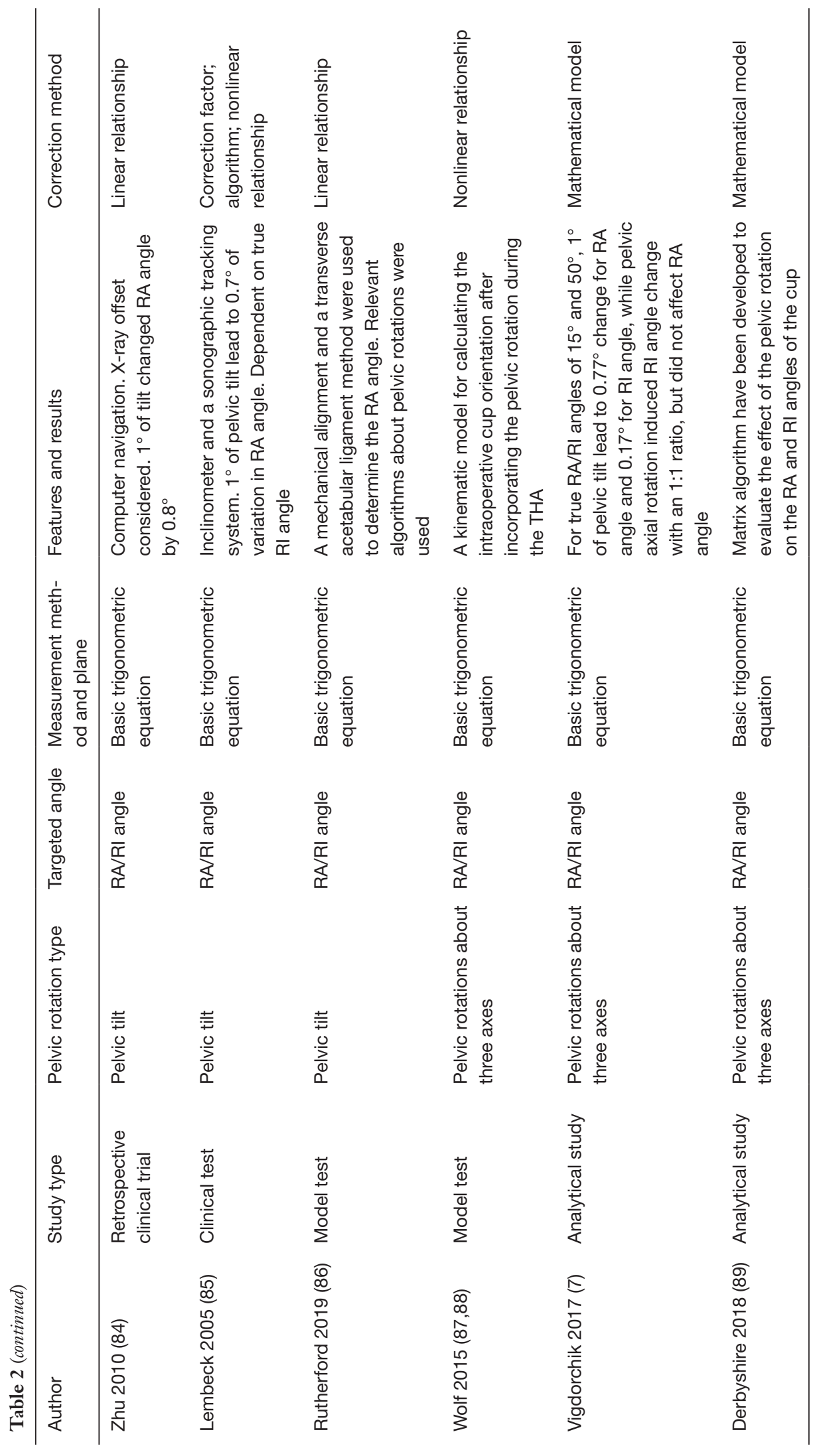


Kerrigan introduced the cone model to calculate the RA/ RI angles of the cup and their true value in 3D space (95). Nevertheless, to reduce the computational difficulty, a simplified situation was simulated with the $\mathrm{X}$-ray beam source directing at the cup's centre, which was similar to the hip-centred AP radiograph.

Based on the related algorithms of projection transformation and monocular computer vision (96-98), Zhao et al. generalized a mathematical model of the cone from a hip-centred AP radiograph to a pelvic AP radiograph (10). Based on the ellipse projection, the true RA and RI angles of the cup could be calculated according to the established model. Sarry et al. established an accurate 2D method using only one pelvic AP radiograph to estimate cup wear. According to their method, the cup orientation was calculated with an algorithm in computer vision with the pose estimation based on the back projection of a $3 \mathrm{D}$ circle from the ellipse (99).

\section{Einzel-Bild-Roentgen-Analyse (EBRA)}

Based on a series of radiographs, EBRA was a computeraided method for assessing the migration of arthroplasty implants. The superiority of this method was that only a single pelvic AP radiograph was needed and a specified range of the pelvic rotation could be compensated using its algorithm (100-102). However, a significantly distorted pelvis could not be corrected with this method. Langton et al. validated EBRA for measuring the RA and RI angles of the cup by comparing it to the lateral radiographic method (103).

Lee et al. (104) also validated the EBRA method with the navigation measurements and tested the RA angle measured on a false profile view with that of EBRA. Their results showed a correlation between the results of two groups with a moderate correlation coefficient of 0.56 .

Grammatopoulos et al. used EBRA to measure the cup angles in the lateral decubitus position intraoperatively and in the supine position postoperatively. The mean differences in the RA and RI angles were $1^{\circ}$ and $-2^{\circ}$, respectively (105). In contrast to Vigdorchik et al. (7), Wang et al. used computer-aided design (CAD) software to create computer-generated pelvic AP radiographs following THA to calculate the posture-integrated RA angle after simulated pelvic rotations were applied (106). Their measurements were based on the EBRA method using the APP as a reference. In line with their established formula, $1^{\circ}$ of pelvic tilt could induce a $0.8^{\circ}$ change in the RA angle with predefined RA and RI angles of $15^{\circ}$ and $40^{\circ}$, respectively.

\section{Two synchronized roentgen tubes}

In addition to the previously described methods used in pelvic AP radiographs, there were also other types of radiographic methods used for assessing cup orientation. Different from those using one $\mathrm{X}$-ray beam source, some other methods were based on two roentgen tubes either at right angles to take the AP and lateral radiographs simultaneously or at an acute angle against each other in front of the body, which enabled calculations of the movements of the implants in $3 \mathrm{D}$ space. Similar to EBRA, these systems were also used for evaluating implant migration or wear. During the evaluation, the cup orientation was an essential determinant for calculating wear.

\section{Radio stereometric analysis (RSA)}

Baldursson et al. (107) and Selvik (108) developed the RSA technique using two synchronized roentgen tubes at a $35^{\circ}$ $40^{\circ}$ angle to each other in front of the body. The original method was based on the configuration of several tantalum markers inserted in the bone (109). In Valstar et al.'s study (110), a new measurement method was developed based on the geometry of the implant, which was also called model-based RSA. In their in vitro experiment, the accuracy of the measurement of the cup orientation was approximately $0.35^{\circ}$ on average.

Borlin et al. incorporated a semi-automatic edge detection algorithm into the model-based RSA system to determine the outline and orientation of the cup (111). In a further study by Sarry et al., they modified their previously established single $\mathrm{X}$-ray-based system by using two roentgen tubes in front of the body, similar to the setup of the RSA system (112).

Devane et al. $(42,113,114)$ modified the RSA method by taking the pelvic AP and hip cross-table radiographs simultaneously. Afterwards, the authors developed PolyWare software based on the RSA method and preoperative CT scan data (115). During measurements, two simultaneous ray tracers were used to simulate the AP and lateral radiographs from the CT-derived $3 \mathrm{D}$ model to compensate for the pelvic rotation postoperatively.

In another study, Yuan et al. (116) also used a similar radiographic setup as Devane et al. $(42,113,114)$ but incorporated the reference frame into the modified RSA system to establish a transformation between the phantom and cage radiographs for further calculations. With this 
system, the RA angle of the cup was measured using the ischiolateral method of Tiberi et al. $(38,39)$ in subsequent studies $(117,118)$.

Teeter et al. (118) used the RSA system to compare the change in the cup angles between supine and standing positions. The anteversion and RI angle increased $12^{\circ}$ and $16.2^{\circ}$ from supine to standing, respectively. The cup anteversion, however, was also measured with the ischiolateral method (39).

\section{EOS system}

Different from the RSA system, pelvic AP and lateral radiographs were taken using two roentgen tubes orthogonal to each other in the EOS system (119). Lazennec et al. introduced the 2D EOS system to measure the cup orientation (120). With this system, the OA and RI angles of the cup, which were also named the frontal and sagittal inclination angles in their study, were measured (121).

Thereafter, Journé et al. aimed to verify the accuracy of this system by comparing it with CT-derived measurement (122). However, in this phantom study, the AA angle of the cup was measured with the CT-based method, and the differences in the anteversion and RI angles between the two methods were $3.9^{\circ}$ and $2.6^{\circ}$, respectively. Tokunaga et al. also measured the AA and RI angles by using the EOS and 3D-CT methods (123). The mean differences in the $\mathrm{AA}$ and RI angles were $0.1^{\circ}$ and $2.3^{\circ}$, respectively, between the two methods. Bendaya et al. also used the EOS system to evaluate the cup angles (124). Nevertheless, the AA angle that they reported was actually the OA angle of the cup.

In contrast to the misuse in the previous three studies, Polkowski et al. used the same definition of cup anteversion in the sagittal plane when comparing the measurement results using both the standing EOS and supine CT methods (125). Their results showed that the difference between the standing and supine $\mathrm{OA}$ angles was almost greater than $5^{\circ}$.

After simulating the standing radiograph using the intraoperative $\mathrm{C}$-arm, Harold et al. compared the intraoperative measurements of the RA and RI angles of the cup using RadLink with those of the postoperative EOS system (59). Their results showed that the differences in the RA and RI angles were $3.3^{\circ}$ and $0.3^{\circ}$, respectively, on average.

\section{D-3D registration method}

In addition to the various radiographic measurement tools and methods mentioned above, the CAD technique was also introduced to develop a more accurate method.

Penney et al. established a preoperative CT-based 2D$3 \mathrm{D}$ registration method for evaluation of the RA and RI angles postoperatively (126). Using the postoperative CTbased $3 \mathrm{D}-3 \mathrm{D}$ registration method as the gold standard, they validated the superior accuracy of this new 2D-3D method to the radiographic method.

In contrast to the $2 \mathrm{D}-3 \mathrm{D}$ registration using one single AP radiograph, Kobayashi et al. (127) developed a 2D-3D matching procedure based on a biplanar X-ray system and the preoperative CT image. However, no details of the measurement method were reported in their study. Craiovan et al. developed a vector arithmetic method based on $2 \mathrm{D}-3 \mathrm{D}$ registration, while the $\mathrm{X}$-ray offset was not considered in their system (128).

Zheng et al. proposed a 2D-3D registration method and the associated software called "HipMatch" for cup placement in THA (129). They validated this with in vitro experiments and cadaveric and clinical studies of THA operations $(130,131)$. In their further modified system, a statistical shape model was used to substitute the preoperative CT-based 3D model to perform the 2D-3D registration with the postoperative pelvic AP radiograph (132).

To evaluate the effect of pelvic rotation, both Blendea et al. (133) and Tannast et al. (134) used 2D-3D matching software to align the preoperative pelvic $3 \mathrm{D}$ model to the postoperative pelvic X-ray. Blendea et al. (133) determined a linear negative correlation between the pelvic flexion and the RI angle, while Tannast et al. (134) presented two nomograms of the relationships between the pelvic tilt and longitudinal rotation and the RA and RI angles.

In a clinical study, Steppacher et al. validated an automated 2D-3D registration algorithm by using the HipNav navigation software to measure the cup orientation (131). Nevertheless, the $\mathrm{X}$-ray offset was also neglected by the Ackland algorithm used in their method. In another clinical study, Yun et al. used 2D-3D matching software to compare the difference in the RA angles between the supine and standing positions and found that there was a negative correlation of the pelvic longitudinal rotation with the RA angle of the right cup but a positive correlation with the left cup in both supine and standing positions $(135,136)$.

\section{Discussion}

The plain radiograph remains the mainstream tool for evaluation of the cup orientation intra- or postoperatively. 
Most of these algorithms were developed based on the ellipse projection from the circle of the cup's opening, which can be connected with each other via the general equation of the ellipse. However, these methods can only be used in standardized hip-centred AP radiographs without considering other biases from the inherent and extrinsic factors, such as the pelvic rotation and X-ray offset. As most evaluation methods of the cup orientation were performed in a retrospective manner, the pelvic AP radiograph might be superior to the hip AP radiograph in terms of viewing the bilateral hips to evaluate the pelvic rotation.

With regard to the X-ray offset, most of the methods used for the pelvic AP radiograph will definitely lead to errors in measurements. Although some studies aimed to find the most accurate method by comparing previous methods with CT-based measurements, their methods and results were not reliable if the pelvic AP radiograph was analysed without considering the $\mathrm{X}$-ray offset. Moreover, the pelvic AP radiographic method was considered to be the reference standard in some comparative studies. Even in some recent studies using advanced equipment, such as the RSA system, the original ellipse method was still used for measuring the RI angle on the pelvic AP radiograph without incorporating the $\mathrm{X}$-ray offset (118).

Those investigations concentrating on the difference between the postoperative pelvic AP radiographic measurements and their intraoperative counterparts or postoperative hip AP radiograph-derived results actually aimed to reveal the effects of the X-ray offset and establish a relationship between the cup orientation and the radiographic angles measured on the pelvic AP radiograph. Additionally, some in vitro experiments on phantom models were carried out to establish a linear relationship between the true radiographic angles and their projected counterparts. In addition to the X-ray offset caused by the variable cup positions, the influencing effects from the cup itself were also addressed by some researchers, which meant that the varying measurements of the radiographic angles of the cup would be changed depending on the different true $\mathrm{RI}$ angles of the cup (48). By establishing a mathematical cone model that included the potential influencing factors of X-ray offset and position, Zhao et al. studied the relationship between the variable orientations and positions of the cup and its RA and RI angles measured on pelvic AP radiographs (68).

Furthermore, pelvic rotation is another important influencing factor that has been extensively studied previously. Some studies were conducted on a phantom model, while others measured the intraoperative cup orientation and pelvic rotation using a navigation system. Most of these studies only determined a rough, linear relationship between the cup angles and pelvic rotation. Meanwhile, there were also some mathematical simulation studies on this issue. However, the X-ray offset was neglected in most of these studies and was not incorporated into the established models. As the pelvic obliqueness and axial rotation could be viewed and adjusted when the pelvic $\mathrm{AP}$ radiograph was taken, the pelvic tilt became the only uncertain parameter that could not be evaluated on the pelvic AP radiograph but still significantly influenced the radiographic evaluation of the cup angle when the patient's posture varied between the supine, standing and even lateral decubitus positions. Prior studies paid much attention to the effects of the pelvic tilt, most of which aimed to determine the difference in the RA and RI angles of the cup between the supine and standing positions. Additionally, some correction factors were proposed to varying degrees in different studies, while some descriptive models were deduced with linear or nonlinear relationships between the pelvic rotation and anatomical parameters acquired from the pelvic AP radiograph. Unfortunately, for those mathematical models presented with analytical equations or formulae, not all essential parameters were incorporated (85).

To be honest, both the effects of the X-ray offset and pelvic rotations actually depend on several parameters, including the spatial orientation and position of the cup and the X-ray source (e.g., the vertical and transverse distances between the cup's centre and the X-ray source, and the distance of the $\mathrm{X}$-ray source relative to the $\mathrm{X}$-ray plane) and the diameter of the cup's opening circle. As most of the previous studies did not report all the details of these important parameters, it is inappropriate to perform a direct comparison among these results under different conditions. The best way to do so is to reveal the changing rules of the effects of the $\mathrm{X}$-ray offset and pelvic rotations on the radiographic angles of the cup in the form of figures, such as curves or surfaces, which enable the analysis of all the potential influencing factors under different situations. In another analytical study, Zhao et al. simulated different types of pelvic rotations and their effects on the RA and RI angles of the cup using a mathematical cone model (90). In contrast to previously established models simulating pelvic rotations, Zhao et al.'s model incorporated the X-ray offset and other influencing factors. The quantitative relationship between different types of pelvic rotation and the RA and RI angles of the cup can be determined by adjusting the 
different positions and true orientations of the cup.

With regard to methods to correct the X-ray offset or pelvic rotation, various types of techniques and equipment have been developed that can be classified into one or two radiograph-based methods or 3D-CT model-based methods. If the measurement was performed on the pelvic $\mathrm{AP}$ radiograph, the opening circle of the cup was the most easily identifiable target on the radiograph that could be connected with its spatial counterpart. A few algorithms have been established based on the related geometric transformation. However, most of them have limitations or preconditions. Based on computer vision technology, Zhao et al. used a cone model to address this question in their theoretical study (10). However, there were limitations to their algorithm. First, the pelvic rotation cannot be corrected by their model. Second, the ellipse silhouette of the cup opening has to be outlined manually. For radiographs of THA lacking the circular marker of the cup opening, an automatic edge detection technique can be used to improve the accuracy and expedite the process of outlining the ellipse, as has been used in Sarry et al.'s study (99). Regarding the bias from the pelvic rotation, although the EBRA system could provide compensation to some degree, the $\mathrm{X}$-ray offset was not incorporated in this system.

In addition to the algorithms and techniques used for pelvic AP radiographs, some advanced techniques and equipment, which were developed mainly for evaluating prosthesis migration or wear, could also be used as an alternative to measuring cup orientation. With regard to the RSA system, there have been mainly three types of variants since its arrival: the model-based RSA, the 3D-CTbased RSA with cross-table radiograph, and the reference marker-based RSA with cross-table radiograph. Although no comparative studies were performed to identify the most accurate of the three variants, their characteristics can also be distinguished from one other. The modelbased RSA combined projection transformation and edge detection. Although the 3D-CT-based RSA system utilized $2 \mathrm{D}-3 \mathrm{D}$ registration, the cross-table lateral radiograph used in this system has the potential bias of causing the pelvic posterior tilt via contralateral hip flexion $(42,113,114)$. A similar problem exists in the latest RSA variant system. Without using the cross-table radiograph, the EOS system substitutes the pelvic AP and lateral radiographs. However, no algorithms for projection transformation and edge detection were used in this system, and the measured cup angles primarily included the $\mathrm{RI}$ and $\mathrm{OA}$ angles, the latter of which was difficult to precisely recognize and measure from the lateral view because of the rounded, impossibly identifiable vertices of the ellipse (121).

The 2D-3D registration method seems to be the most accurate measurement method for determining the RA and RI angles of the cup. The advantage of this method is that both the X-ray offset and pelvic rotation can be evaluated based on the reconstructed 3D model, with which the RA and RI angles were measured as the ground truth. To increase the accuracy of $2 \mathrm{D}-3 \mathrm{D}$ registration, Kobayashi et al. (127) introduced a potential alternative with 2D-3D registration and biplanar $\mathrm{X}$-ray in the standing posture, but no further studies have been performed on it.

\section{Challenges and future prospects in radiographic assessment of the cup orientation}

In addition to postoperative evaluation, precisely determining the cup orientation intraoperatively may be the optimal measure for preventing late complications related to malpositioning of the cup. In a clinical study, Steppacher et al. validated an automated 2D-3D registration algorithm by using HipNav navigation software to determine the cup orientation intraoperatively (131). Nevertheless, the $\mathrm{X}$-ray offset was neglected by the version of Ackland's method used in their study. Yamada et al. verified that the accuracy of the cup placement in a preoperative CT-based 2D-3D registration system was superior to that of the paired-point matched system in THA when compared with the postoperative CT scan (137).

Different from CT-based navigation, some imageless navigation systems were also developed to improve cup positioning in THA $(138,139)$. Furthermore, augmented reality technology has also been used as a powerful alternative to the current navigation system for cup placement (140-142). With the rapid development of artificial intelligence, machine learning, and computer vision $(143,144)$, the collection, processing, and integration of pre-, intra-, and postoperative multimodal data could be performed in a more efficient and accurate manner, which could then be incorporated into robot-assisted orthopaedic surgery system in the field of intelligent orthopaedics in the future $(145,146)$. Before that, however more high-quality theoretical, in vitro, and clinical studies should be performed in a robust manner.

\section{Acknowledgments}

Funding: This work was supported partially by the 
Fundamental Research Funds for the Central Universities [FRF-TP-19-015A2 to RXX].

\section{Footnote}

Conflicts of Interest: The authors have no conflicts of interest to declare.

Ethical Statement: The authors are accountable for all aspects of the work in ensuring that questions related to the accuracy or integrity of any part of the work are appropriately investigated and resolved.

\section{References}

1. Müller ME. Total hip prostheses. Clin Orthop Relat Res 1970;72:46-68.

2. McLaren RH. Prosthetic hip angulation. Radiology 1973;107:705-6.

3. Lewinnek GE, Lewis JL, Tarr R, et al. Dislocations after total hip-replacement arthroplasties. J Bone Joint Surg [Am] 1978;60:217-20.

4. Murray DW. The definition and measurement of acetabular orientation. J Bone Joint Surg (Br) 1993;75:228-32.

5. Penenberg BL, Samagh SP, Rajaee SS, et al. Digital Radiography in Total Hip Arthroplasty: Technique and Radiographic Results. J Bone Joint Surg Am 2018;100:226-35.

6. Sariali E, Boukhelifa N, Catonne Y, et al. Comparison of Three-Dimensional Planning-Assisted and Conventional Acetabular Cup Positioning in Total Hip Arthroplasty: A Randomized Controlled Trial. J Bone Joint Surg Am 2016;98:108-16.

7. Vigdorchik JM, Muir JM, Buckland A, et al. Undetected Intraoperative Pelvic Movement Can Lead to Inaccurate Acetabular Cup Component Placement during Total Hip Arthroplasty: A Mathematical Simulation Estimating Change in Cup Position. The Journal of Hip Surgery 2017;1:186-93.

8. Snijders TE, Willemsen K, van Gaalen SM, et al. Lack of consensus on optimal acetabular cup orientation because of variation in assessment methods in total hip arthroplasty: a systematic review. Hip Int 2019;29:41-50.

9. Beckmann J, Luring C, Tingart $M$, et al. Cup positioning in THA: current status and pitfalls. A systematic evaluation of the literature. Arch Orthop Trauma Surg 2009;129:863-72.

10. Zhao JX, Su XY, Xiao RX, et al. A mathematical method for precisely calculating the radiographic angles of the cup after total hip arthroplasty. Med Eng Phys 2016;38:1376-81.

11. Ackland MK, Bourne WB, Uhthoff HK. Anteversion of the acetabular cup. Measurement of angle after total hip replacement. J Bone Joint Surg [Br] 1986;68:409-13.

12. Pettersson H, Gentz CF, Lindberg HO, et al. Radiologic evaluation of the position of the acetabular component of the total hip prosthesis. Acta Radiol Diagn (Stockh) 1982;23:259-63.

13. Herrlin K, Selvik G, Pettersson H. Space orientation of total hip prosthesis. A method for three-dimensional determination. Acta Radiol Diagn (Stockh) 1986;27:619-27.

14. Herrlin K, Pettersson H, Selvik G. Comparison of two- and three-dimensional methods for assessment of orientation of the total hip prosthesis. Acta Radiol 1988;29:357-61.

15. Hassan DM, Johnston GH, Dust WN, et al. Radiographic calculation of anteversion in acetabular prostheses. J Arthroplasty 1995;10:369-72.

16. Pradhan R. Planar anteversion of the acetabular cup as determined from plain anteroposterior radiographs. J Bone Joint Surg [Br] 1999;81:431-5.

17. Saka G, Altun G, Burc H, et al. A new radiographic acetabular cup anteversion measurement method in total hip arthroplasty: a clinical study. Eur J Orthop Surg Traumatol 2019;29:813-8.

18. Visser JD, Konings JG. A new method for measuring angles after total hip arthroplasty. A study of the acetabular cup and femoral component. J Bone Joint Surg Br 1981;63B:556-9.

19. Bader R, Barbano R, Wörtler K, et al. Positionsbestimmung der künstlichen Hüftpfanne mittels Standard-Röntgenaufnahmen: Einfluss der Beckenkippung. Jahrestagung Süddeutscher Orthopäden Orthopädische Praxis, Sonderausgabe zur 2004;52:242-3.

20. Liaw CK, Hou SM, Yang RS, et al. A new tool for measuring cup orientation in total hip arthroplasties from plain radiographs. Clin Orthop Relat Res 2006;451:134-9.

21. Kosiyatrakul A, Luenam S, Chotanaphuti T. Measurement of acetabular cup anteversion with the circle theorem. J Med Assoc Thai 2009;92:S128-33.

22. Bachhal V, Jindal N, Saini G, et al. A new method of measuring acetabular cup anteversion on simulated radiographs. Int Orthop 2012;36:1813-8.

23. Fabeck L, Farrokh D, Tolley M, et al. A method to measure acetabular cup anteversion after total hip replacement. Acta Orthop Belg 1999;65:485-91. 
24. Delagrammaticas DE, Ochenjele G, Rosenthal BD, et al. Intraoperative evaluation of acetabular cup position during anterior approach total hip arthroplasty: are we accurately interpreting? Hip Int 2020;30:40-7.

25. Liaw CK, Wu TY, Hou SM, et al. Computerized ellipse method for measuring acetabular version after total hip replacement--a precision study using synthetic and real radiographs. Comput Aided Surg 2013;18:195-200.

26. Zingg M, Boudabbous S, Hannouche D, et al. Standardized fluoroscopy-based technique to measure intraoperative cup anteversion. J Orthop Res 2017;35:2307-12.

27. Opperer M, Lee YY, Nally F, et al. A critical analysis of radiographic factors in patients who develop dislocation after elective primary total hip arthroplasty. Int Orthop 2016;40:703-8.

28. Boettner F, Zingg M, Emara AK, et al. The Accuracy of Acetabular Component Position Using a Novel Method to Determine Anteversion. J Arthroplasty 2017;32:1180-5.

29. Schwarzkopf R, Vigdorchik JM, Miller TT, et al. Quantification of Imaging Error in the Measurement of Cup Position: A Cadaveric Comparison of Radiographic and Computed Tomography Imaging. Orthopedics 2017;40:e952-8.

30. Martell JM, Berdia S. Determination of polyethylene wear in total hip replacements with use of digital radiographs. J Bone Joint Surg Am 1997;79:1635-41.

31. Barrack RL, Krempec JA, Clohisy JC, et al. Accuracy of acetabular component position in hip arthroplasty. J Bone Joint Surg Am 2013;95:1760-8.

32. Callanan MC, Jarrett B, Bragdon CR, et al. The John Charnley Award: risk factors for cup malpositioning: quality improvement through a joint registry at a tertiary hospital. Clin Orthop Relat Res 2011;469:319-29.

33. Sah AP, Estok DM, 2nd. Dislocation rate after conversion from hip hemiarthroplasty to total hip arthroplasty. J Bone Joint Surg Am 2008;90:506-16.

34. Woo RY, Morrey BF. Dislocations after total hip arthroplasty. J Bone Joint Surg Am 1982;64:1295-306.

35. Nunley RM, Keeney JA, Zhu J, et al. The reliability and variation of acetabular component anteversion measurements from cross-table lateral radiographs. J Arthroplasty 2011;26:84-7.

36. McArthur B, Cross M, Geatrakas C, et al. Measuring acetabular component version after THA: CT or plain radiograph? Clin Orthop Relat Res 2012;470:2810-8.

37. Reikeras O, Gunderson RB. Cross table lateral radiography for measurement of acetabular cup version. Ann Transl Med 2016;4:169.
38. Pulos N, Tiberi Iii JV, 3rd, Schmalzried TP. Measuring acetabular component position on lateral radiographs ischio-lateral method. Bull NYU Hosp Jt Dis 2011;69 Suppl 1:S84-9.

39. Tiberi JV, Pulos N, Kertzner M, et al. A more reliable method to assess acetabular component position. Clin Orthop Relat Res 2012;470:471-6.

40. Snijders TE, Schlosser TPC, van Gaalen SM, et al. Non-equivalent Results from Different Anteversion Measurements Methods for the Evaluation of the Acetabular Cup Orientation in Total Hip Arthroplasty. Orthop Surg 2019;11:241-7.

41. Nishino H, Nakamura S, Arai N, et al. Accuracy and precision of version angle measurements of the acetabular component after total hip arthroplasty. J Arthroplasty 2013;28:1644-7.

42. Devane PA, Bourne RB, Rorabeck CH, et al. Measurement of polyethylene wear in metal-backed acetabular cups.

I. Three-dimensional technique. Clin Orthop Relat Res 1995;319:303-16.

43. Ghelman B, Kepler CK, Lyman S, et al. CT outperforms radiography for determination of acetabular cup version after THA. Clin Orthop Relat Res 2009;467:2362-70.

44. Reito A, Puolakka T, Paakkala A, et al. Assessment of inter- and intra-observer reliability in the determination of radiographic version and inclination of the cup in metal-on-metal hip resurfacing. Int Orthop 2012;36:519-25.

45. Mahmood SS, Al-Amiry B, Mukka SS, et al. Validity, reliability and reproducibility of plain radiographic measurements after total hip arthroplasty. Skeletal Radiol 2015;44:345-51.

46. Haenle M, Mittelmeier W, Barbano R, et al. Accuracy and reliability of different methods to evaluate the acetabular cup version from plain radiographs. Surg Radiol Anat 2010;32:725-30.

47. Nho JH, Lee YK, Kim HJ, et al. Reliability and validity of measuring version of the acetabular component. J Bone Joint Surg [Br] 2012;94:32-6.

48. Widmer KH. A simplified method to determine acetabular cup anteversion from plain radiographs. J Arthroplasty 2004;19:387-90.

49. Marx A, von Knoch M, Pfortner J, et al. Misinterpretation of cup anteversion in total hip arthroplasty using planar radiography. Arch Orthop Trauma Surg 2006;126:487-92.

50. Kalteis T, Handel M, Herold T, et al. Position of the acetabular cup -- accuracy of radiographic calculation compared to CT-based measurement. Eur J Radiol 
2006;58:294-300.

51. Bayraktar V, Weber M, von Kunow F, et al. Accuracy of measuring acetabular cup position after total hip arthroplasty: comparison between a radiographic planning software and three-dimensional computed tomography. Int Orthop 2017;41:731-8.

52. Lu M, Zhou YX, Du H, et al. Reliability and validity of measuring acetabular component orientation by plain anteroposterior radiographs. Clin Orthop Relat Res 2013;471:2987-94.

53. Westacott DJ, McArthur J, King RJ, et al. Assessment of cup orientation in hip resurfacing: a comparison of TraumaCad and computed tomography. J Orthop Surg Res 2013;8:8.

54. Nomura T, Naito M, Nakamura Y, et al. An analysis of the best method for evaluating anteversion of the acetabular component after total hip replacement on plain radiographs. Bone Joint J 2014;96-B:597-603.

55. Alzohiry MA, Abdelnasser MK, Moustafa M, et al. Accuracy of plain antero-posterior radiographic-based methods for measurement of acetabular cup version. Int Orthop 2018;42:2777-85.

56. Dorr LD, Wolf AW, Chandler R, et al. Classification and treatment of dislocations of total hip arthroplasty. Clin Orthop Relat Res 1983;173:151-8.

57. Wan Z, Malik A, Jaramaz B, et al. Imaging and navigation measurement of acetabular component position in THA. Clin Orthop Relat Res 2009;467:32-42.

58. Shin WC, Lee SM, Lee KW, et al. The reliability and accuracy of measuring anteversion of the acetabular component on plain anteroposterior and lateral radiographs after total hip arthroplasty. Bone Joint J 2015;97-B:611-6.

59. Harold RE, Delagrammaticas D, Keller T, et al. Are single plane intraoperative and biplanar postoperative radiographic measurements of acetabular cup position the same? Hip Int 2019;Jun 27:1120700019859902.

60. Amirouche F, Solitro GF, Chandrasekaran S, et al. Validating a Modified Circle Theorem Method for the Measurement of Acetabular Cup Anteversion on Plain Radiography with Intra-Operative Data from Robotic Assisted Total Hip Arthroplasty. J Arthroplasty 2016;31:323-9.

61. Goergen TG, Resnick D. Evaluation of acetabular anteversion following total hip arthroplasty: necessity of proper centring. Br J Radiol 1975;48:259-60.

62. Dorr LD, Wan Z. Causes of and treatment protocol for instability of total hip replacement. Clin Orthop Relat Res
1998;355:144-51.

63. Dorr LD, Bechtol CO, Watkins RG, et al. Radiographic anatomic structure of the arthritic acetabulum and its influence on total hip arthroplasty. J Arthroplasty 2000;15:890-900.

64. Rueckl K, Alcaide DJ, Springer B, et al. Intraoperative measurement of cup inclination using fluoroscopy requires a correction factor. Arch Orthop Trauma Surg 2019;139:1511-7.

65. Widmer D, Reising K, Kotter E, et al. Correct Assessment of Acetabular Component Orientation in Total Hip Arthroplasty From Plane Radiographs. J Arthroplasty 2018;33:2652-9.e3.

66. Liaw CK, Yang RS, Hou SM, et al. Measurement of the acetabular cup anteversion on simulated radiographs. J Arthroplasty 2009;24:468-74.

67. Schwarz T, Weber M, Worner M, et al. Central $\mathrm{X}$-ray beam correction of radiographic acetabular cup measurement after THA: an experimental study. Int J Comput Assist Radiol Surg 2017;12:829-37.

68. Zhao JX, Su XY, Zhao Z, et al. Three-dimensional orientation and location-dependent varying rules of radiographic angles of the acetabular cup. Int Orthop 2018;42:1819-25.

69. Shon WY, Gupta S, Biswal S, et al. Validation of a simple radiographic method to determine variations in pelvic and acetabular cup sagittal plane alignment after total hip arthroplasty. Skeletal Radiol 2008;37:1119-27.

70. Heckmann N, McKnight B, Stefl M, et al. Late Dislocation Following Total Hip Arthroplasty: Spinopelvic Imbalance as a Causative Factor. J Bone Joint Surg Am 2018;100:1845-53.

71. Anda S, Svenningsen S, Grontvedt T, et al. Pelvic inclination and spatial orientation of the acetabulum. A radiographic, computed tomographic and clinical investigation. Acta Radiol 1990;31:389-94.

72. Lazennec JY, Charlot N, Gorin M, et al. Hip-spine relationship: a radio-anatomical study for optimization in acetabular cup positioning. Surg Radiol Anat 2004;26:136-44.

73. Tannast M, Zheng G, Anderegg C, et al. Tilt and rotation correction of acetabular version on pelvic radiographs. Clin Orthop Relat Res 2005;438:182-90.

74. Lubovsky O, Wright D, Hardisty M, et al. Acetabular orientation: anatomical and functional measurement. Int J Comput Assist Radiol Surg 2012;7:233-40.

75. Delagrammaticas DE, Alvi HM, Kaat AJ, et al. Quantitative Effect of Pelvic Position on Radiographic Assessment of Acetabular Component Position. 
J Arthroplasty 2018;33:608-14.e1.

76. Tannast M, Murphy SB, Langlotz F, et al. Estimation of pelvic tilt on anteroposterior $\mathrm{X}$-rays--a comparison of six parameters. Skeletal Radiol 2006;35:149-55.

77. Snijders TE, Schlosser TPC, van Gaalen SM, et al. Trigonometric Algorithm Defining the True ThreeDimensional Acetabular Cup Orientation: Correlation Between Measured and Calculated Cup Orientation Angles. JB JS Open Access 2018;3:e063.

78. Thoren B, Sahlstedt B. Influence of pelvic position on radiographic measurements of the prosthetic acetabular component. An experimental study on a pelvic model. Acta Radiol 1990;31:133-6.

79. Mellano CR, Spitzer AI. How does pelvic rotation or tilt affect radiographic measurement of acetabular component inclination angle during THA? J Orthop 2015;12:222-7.

80. Schwarz TJ, Weber M, Dornia C, et al. Correction of pelvic tilt and pelvic rotation in cup measurement after THA - an experimental study. Rofo 2017;189:864-73.

81. Grammatopoulos G, Gofton W, Cochran M, et al. Pelvic positioning in the supine position leads to more consistent orientation of the acetabular component after total hip arthroplasty. Bone Joint J 2018;100-b:1280-8.

82. Liaw CK, Yang RS, Hou SM, et al. A Simple Mathematical Standardized Measurement of Acetabulum Anteversion after Total Hip Arthroplasty. Comput Math Methods Med 2008;9:105-19.

83. Malik A, Wan Z, Jaramaz B, et al. A validation model for measurement of acetabular component position. J Arthroplasty 2010;25:812-9.

84. Zhu J, Wan Z, Dorr LD. Quantification of pelvic tilt in total hip arthroplasty. Clin Orthop Relat Res 2010;468:571-5.

85. Lembeck B, Mueller O, Reize P, et al. Pelvic tilt makes acetabular cup navigation inaccurate. Acta Orthop 2005;76:517-23.

86. Rutherford M, O'Connor JD, Gill HS, et al. Operative and radiographic acetabular component orientation in total hip replacement: Influence of pelvic orientation and surgical positioning technique. Med Eng Phys 2019;64:7-14.

87. Wolf A, DiGioia AM 3rd, Mor AB, et al. A kinematic model for calculating cup alignment error during total hip arthroplasty. J Biomech 2005;38:2257-65.

88. Wolf A, Digioia AM 3rd, Mor AB, et al. Cup alignment error model for total hip arthroplasty. Clin Orthop Relat Res 2005;437:132-7.

89. Derbyshire B. Correction of radiographic measurements of acetabular cup wear for variations in pelvis orientation.
Proc Inst Mech Eng H 2018;232:299-309.

90. Zhao JX, Su XY, Zhao Z, et al. The synergetic effect of pelvic rotation and $\mathrm{X}$-ray offset on radiographic angles of the acetabular cup. Med Biol Eng Comput 2019;57:2359-71.

91. Seradge H, Nagle KR, Miller RJ. Analysis of version in the acetabular cup. Clin Orthop Relat Res 1982;166:152-7.

92. Jaramaz B, DiGioia AM 3rd, Blackwell M, et al. Computer assisted measurement of cup placement in total hip replacement. Clin Orthop Relat Res 1998;354:70-81.

93. Derbyshire B. Correction of acetabular cup orientation measurements for X-ray beam offset. Med Eng Phys 2008;30:1119-26.

94. Amiri S, Masri BA, Garbuz D, et al. A multiplanar radiography method for assessing cup orientation in total hip arthroplasty. J Biomech Eng 2012;134:101008.

95. Stuart Kerrigan C, McKenna SJ, Ricketts IW, et al. Automated assessment of polyethylene wear in cemented acetabular components using anteroposterior radiographs of total hip replacements. Comput Med Imaging Graph 2008;32:221-38.

96. Ahn SJ, Warnecke HJ, Kotowski R. Systematic geometric image measurement errors of circular object targets: mathematical formulation and correction. Photogramm Rec 1999;16:485-502.

97. Ferri M, Mangili F, Viano G. Projective Pose Estimation of Linear and Quadratic Primitives in Monocular Computer Vision. CVGIP: Image Understanding 1993;58:66-84.

98. Forsyth D, Mundy JL, Zisserman A, et al. Invariant descriptors for 3-D object recognition and pose. IEEE $T$ Pattern Anal 1991;13:971-91.

99. Sarry L, Tilmant C, Boisgard S, et al. Monitoring of polyethylene wear in nonmetal-backed acetubular cups by digitized anteroposterior pelvic radiography. IEEE Trans Med Imaging 2003;22:1172-82.

100.Krismer M, Bauer R, Tschupik J, et al. EBRA: a method to measure migration of acetabular components. J Biomech 1995;28:1225-36.

101.Ilchmann T, Kesteris U, Wingstrand H. EBRA improves the accuracy of radiographic analysis of acetabular cup migration. Acta Orthop Scand 1998;69:119-24.

102. Hendrich C, Bahlmann J, Eulert J. Migration of the uncemented Harris-Galante acetabular cup: results of the einbildroentgenanalyse (EBRA) method. J Arthroplasty 1997;12:889-95.

103.Langton DJ, Sprowson AP, Mahadeva D, et al. Cup anteversion in hip resurfacing: validation of EBRA and the presentation of a simple clinical grading system. J Arthroplasty 2010;25:607-13. 
104. Lee JK, Sardana V, White C, et al. Cup version can be accurately measured on the false profile view radiograph. Hip Int 2014;24:347-54.

105. Grammatopoulos G, Pandit HG, da Assuncao R, et al. The relationship between operative and radiographic acetabular component orientation: which factors influence resultant cup orientation? Bone Joint J 2014;96-b:1290-7.

106. Wang L, Thoreson AR, Trousdale RT, et al. Radiographic cup anteversion measurement corrected from pelvic tilt. Med Eng Phys 2017;49:103-8.

107. Baldursson H, Egund N, Hansson LI, et al. Instability and wear of total hip prostheses determined with roentgen stereophotogrammetry. Arch Orthop Trauma Surg 1979;95:257-63.

108. Selvik G. Roentgen stereophotogrammetry. A method for the study of the kinematics of the skeletal system. Acta Orthop Scand Suppl 1989;232:1-51.

109. Karrholm J, Herberts P, Hultmark P, et al. Radiostereometry of hip prostheses. Review of methodology and clinical results. Clin Orthop Relat Res 1997;344:94-110.

110. Valstar ER, Spoor CW, Nelissen RG, et al. Roentgen stereophotogrammetric analysis of metal-backed hemispherical cups without attached markers. J Orthop Res 1997;15:869-73.

111. Borlin N, Rohrl SM, Bragdon CR. RSA wear measurements with or without markers in total hip arthroplasty. J Biomech 2006;39:1641-50.

112. Sarry L, Descamps S, Boisgard S, et al. Radiographic stereometry for non-metal-backed acetubular cups: 3D wear estimation and related uncertainty. Med Image Anal 2005;9:267-79.

113. Devane PA, Horne JG, Martin K, et al. Three-dimensional polyethylene wear of a press-fit titanium prosthesis. Factors influencing generation of polyethylene debris. J Arthroplasty 1997;12:256-66.

114. Devane PA, Horne JG. Assessment of polyethylene wear in total hip replacement. Clin Orthop Relat Res 1999;369:59-72.

115. Devane P, Horne J, Foley G, et al. Measuring the migration of the components and polyethylene wear after total hip arthroplasty: beads and specialised radiographs are not necessary. Bone Joint J 2017;99-B:1290-7.

116. Yuan X, Lam Tin Cheung K, Howard JL, et al. Radiostereometric analysis using clinical radiographic views: Validation measuring total hip replacement wear. J Orthop Res 2016;34:1521-8.
117. Goyal P, Howard JL, Yuan X, et al. Effect of Acetabular Position on Polyethylene Liner Wear Measured Using Simultaneous Biplanar Acquisition. J Arthroplasty 2017;32:1670-4.

118. Teeter MG, Goyal P, Yuan X, et al. Change in Acetabular Cup Orientation From Supine to Standing Position and Its Effect on Wear of Highly Crosslinked Polyethylene. J Arthroplasty 2018;33:263-7.

119. Yan $W, \mathrm{Xu} X, \mathrm{Xu} Q$, et al. Femoral and tibial torsion measurements based on EOS imaging compared to 3D CT reconstruction measurements. Ann Transl Med 2019;7:460.

120.Lazennec JY, Rousseau MA, Rangel A, et al. Pelvis and total hip arthroplasty acetabular component orientations in sitting and standing positions: measurements reproductibility with EOS imaging system versus conventional radiographies. Orthop Traumatol Surg Res 2011;97:373-80.

121.Lazennec JY, Rousseau MA, Brusson A, et al. Total Hip Prostheses in Standing, Sitting and Squatting Positions: An Overview of Our 8 Years Practice Using the EOS Imaging Technology. Open Orthop J 2015;9:26-44.

122.Journé A, Sadaka J, Belicourt C, et al. New method for measuring acetabular component positioning with EOS imaging: feasibility study on dry bone. Int Orthop 2012;36:2205-9.

123. Tokunaga K, Okamoto M, Watanabe K. Implant Orientation Measurement After THA Using the EOS X-Ray Image Acquisition System. Adv Exp Med Biol 2018;1093:335-43.

124. Bendaya S, Anglin C, Lazennec JY, et al. Good vs Poor Results After Total Hip Arthroplasty: An Analysis Method Using Implant and Anatomic Parameters With the EOS Imaging System. J Arthroplasty 2016;31:2043-52.

125.Polkowski GG, Nunley RM, Ruh EL, et al. Does standing affect acetabular component inclination and version after THA? Clin Orthop Relat Res 2012;470:2988-94.

126.Penney GP, Edwards PJ, Hipwell JH, et al. Postoperative calculation of acetabular cup position using 2-D-3-D registration. IEEE Trans Biomed Eng 2007;54:1342-8.

127. Kobayashi K, Kai S, Sakamoto M, et al. Image registration method for assessing 3D hip alignment and implant position during standing posture. Journal of Biomechanical Science and Engineering 2014;9:13-00162.

128. Craiovan B, Weber M, Worlicek M, et al. Measuring Acetabular Cup Orientation on Antero-Posterior Radiographs of the Hip after Total Hip Arthroplasty with 
a Vector Arithmetic Radiological Method. Is It Valid and Verified for Daily Clinical Practice? Rofo 2016;188:574-81.

129.Zheng G, Zhang X, Steppacher SD, et al. HipMatch: an object-oriented cross-platform program for accurate determination of cup orientation using $2 \mathrm{D}-3 \mathrm{D}$ registration of single standard X-ray radiograph and a CT volume. Comput Methods Programs Biomed 2009;95:236-48.

130.Zheng G, Steppacher S, Zhang X, et al. Precise estimation of postoperative cup alignment from single standard X-ray radiograph with gonadal shielding. Med Image Comput Comput Assist Interv 2007;10:951-9.

131. Steppacher SD, Tannast M, Zheng G, et al. Validation of a new method for determination of cup orientation in THA. J Orthop Res 2009;27:1583-8.

132.Zheng G, von Recum J, Nolte LP, et al. Validation of a statistical shape model-based $2 \mathrm{D} / 3 \mathrm{D}$ reconstruction method for determination of cup orientation after THA. Int J Comput Assist Radiol Surg 2012;7:225-31.

133. Blendea S, Eckman K, Jaramaz B, et al. Measurements of acetabular cup position and pelvic spatial orientation after total hip arthroplasty using computed tomography/ radiography matching. Comput Aided Surg 2005;10:37-43.

134. Tannast M, Langlotz U, Siebenrock KA, et al. Anatomic referencing of cup orientation in total hip arthroplasty. Clin Orthop Relat Res 2005;436:144-50.

135. Yun H, Murphy WS, Ward DM, et al. Effect of Pelvic Tilt and Rotation on Cup Orientation in Both Supine and Standing Positions. J Arthroplasty 2018;33:1442-8.

136. Yun HH, Murphy WS, Ward DM, et al. Effect of pelvic tilt and rotation on cup orientation in standing anteroposterior radiographs. Hip Int 2020;30:48-55.

137. Yamada K, Endo H, Tetsunaga T, et al. Accuracy of Cup Positioning With the Computed Tomography-Based Twodimensional to Three-Dimensional Matched Navigation
System: A Prospective, Randomized Controlled Study. J Arthroplasty 2018;33:136-43.

138. Lin F, Lim D, Wixson RL, et al. Validation of a computer navigation system and a CT method for determination of the orientation of implanted acetabular cup in total hip arthroplasty: a cadaver study. Clin Biomech (Bristol, Avon) 2008;23:1004-11.

139. Bradley MP, Benson JR, Muir JM. Accuracy of Acetabular Component Positioning Using Computer-assisted Navigation in Direct Anterior Total Hip Arthroplasty. Cureus 2019;11:e4478.

140. Grützner PA, Zheng G, Langlotz U, et al. C-arm based navigation in total hip arthroplasty-background and clinical experience. Injury 2004;35 Suppl 1:S-A90-5.

141. Ogawa H, Hasegawa S, Tsukada S, et al. A Pilot Study of Augmented Reality Technology Applied to the Acetabular Cup Placement During Total Hip Arthroplasty. J Arthroplasty 2018;33:1833-7.

142.Logishetty K, Western L, Morgan R, et al. Can an Augmented Reality Headset Improve Accuracy of Acetabular Cup Orientation in Simulated THA? A Randomized Trial. Clin Orthop Relat Res 2019;477:1190-9.

143. Haeberle HS, Helm JM, Navarro SM, et al. Artificial Intelligence and Machine Learning in Lower Extremity Arthroplasty: A Review. J Arthroplasty 2019;34:2201-3.

144. Topol EJ. High-performance medicine: the convergence of human and artificial intelligence. Nat Med 2019;25:44-56.

145.Zhao JX, Li C, Ren H, et al. Evolution and Current Applications of Robot-Assisted Fracture Reduction: A Comprehensive Review. Ann Biomed Eng 2020;48:203-24.

146.Zheng G, Nolte LP. Computer-Aided Orthopaedic Surgery: State-of-the-Art and Future Perspectives. Adv Exp Med Biol 2018;1093:1-20.
Cite this article as: Zhao JX, Su XY, Zhao Z, Xiao RX, Zhang LC, Tang PF. Radiographic assessment of the cup orientation after total hip arthroplasty: a literature review. Ann Transl Med 2020;8(4):130. doi: 10.21037/atm.2019.12.150 